\title{
ANALISIS DESKRIPTIF TEORI PEMEROLEHAN BAHASA
}

\section{KEDUA}

\author{
Dailatus Syamsiyah \\ Dosen STAI Masjid Syuhada Yogyakarta \\ Email: dail_sy@yahoo.com
}

\section{Abstrak}

Akuisisi Bahasa Kedua (SLA) cukup berbeda dengan Second Language Learning (SLL). Krashen mengatakan bahwa SLA mengacu pada kompetensi linguistik dan focuse pada bentuk bahasa yang secara alami diinternalisasi ke dalam pembelajar. Sebaliknya SLL memiliki arti yang berlawanan, itu adalah pembelajaran pengasuhan dan hasil dari situasi pembelajaran formal.

Konteks SLA bersifat alami sedangkan SLL diprogram secara formal. Biasanya orang belajar bahasa demi motivasi berprestasi, meski bisa memperoleh bahasa sebagai motivasi komunikasi. SLL focuse menguasai aturan bahasa sementara SLA berusaha menguasai ketrampilan komunikasi. Penelitian ini bertujuan untuk mendeskripsikan teori akuisisi bahasa kedua yang dikembangkan oleh psikolog sekaligus ahli bahasa seperti B.F. Skinner, Noam Chomsky dan Stephen D Krashen. Ketiganya akan memberi kita wawasan luas tentang aspek konkret empiris serta aspek intuitif abstrak dari perolehan bahasa kedua.

Kata kunci: bahasa, akuisisi

\section{Abstract}

The Second Language Acquisition (SLA) is quite difference with the Second Language Learning (SLL). Krashen said that SLA refers to linguistic competence and focuse on linguistic forms which are naturally internalized into the learner. Instead the SLL has an opposite meaning, it is a nurture learning and a result of formal learning situation.

The context of SLA is natural while the SLL is formally programmed. Usually people learn language for the sake of achievement motivation, inspite of acquiring language as a communication motivation. SLL focuse on mastering the rules of language while SLA trying to master the skill of communication. 
This study aims to describe the theories of second language acquisition developed by psychologists as well as linguists such as B.F. Skinner, Noam Chomsky and Stephen D Krashen. These three will give us such wide insight about an empirical concrete aspect as well as an abstract intuitive aspect of second language acquisition.

Keyword : language, acquisition.

\section{A. Pendahuluan}

Pengertian pemerolehan bahasa (language acquisition) berbeda dengan pembelajaran bahasa (language learning). Menurut Stephen D. Krashen, Pemerolehan bahasa mengacu pada kemampuan linguistic yang telah diinternalisasikan secara alami atau tanpa disadari dan memusatkan pada bentuk-bentuk linguistic (kata-kata). Sedangkan pembelajaran bahasa memiliki pengertian yang sebaliknya, dilakukan dengan sadar dan merupakan hasil situasi belajar formals6. Konteks pemerolehan bersifat alami, sedangkan pembelajaran mengacu pada kondisi formal dengan konteks yang terprogram. Biasanya seseorang yang belajar bahasa disebabkan motivasi prestasi, sedangkan memperoleh bahasa biasanya karena motivasi komunikasi. Belajar bahasa ditekankan untuk menguasai kaidah, sementara perolehan bahasa untuk menguasai ketrampilan berkomunikasis7.

Menurut Stephen D Krashen sistem pemerolehan (acquisition system) adalah proses penguasaan bahasa kedua secara bawah sadar. Maksudnya, formulasi kaidah-kaidah bahasa sasaran dilakukan dan diinternalisasikan secara bawah sadar. Dalam sistem ini, yang dipentingkan adalah isi

56Stephen D. Krashen, Second Acquisition And Second Language Learning, (Pergamon Press Inc, University of Southern California : 1981),hlm. 6 57 Ibid, hlm. 7

60 Jurnal Komunikasi dan Pendidikan Islam, Volume 6, Nomor 2, Desember 2017 
pesan, bukan bentuk linguistiknya atau gramatika wacana. Berbeda dengan system belajar (learning system) dimana terjadi proses asimilasi dan rasionalisasi terhadap kaidah kaidah bahasa kedua sebagai hasil dari pengajaran formal tentang tata bahasa58.

Sesungguhnya model pemerolehan bahasa kedua (second language acquisition/SLA) sangat beraneka ragam. Djoko Saryono dalam pembacaannya terhadap berbagai literatur menyebut teorema, dalil, hipotesis dan teori pemerolehan bahasa kedua ada sekitar 24 model yang kemudian ia golongkan menjadi 4 rumpun, yaitu59: pertama, rumpun Behavioris yang berpangkal pada psikologi behaviorisme karena para pengembangnya adalah para psikolog berpaham behavioris, antara lain; (1). Model pengondisian operan Skinner; (2). Model pelabelan Miller dan Bollad; (3). Model belajar tanda Miller; (4). Model mediasional Osgood; (5). Model staat; dan (6). Model generalisasi kontekstual Braine; dan (7). Model analisis structural Berlyne.

Kedua, rumpun Kognitif berpangkal pada psikologi kognitif dan psikologi gestalt, antara lain; (1). Model perkembangan intelektual Piaget; (2). Model sosiopsikologis Lambert; (3). Model pengganjaran dan penguatan secara sadar Carol; (4). Model neurobiologist atau neurofungsional Lennerberg dan Lamandella; (5). Model konteks sosial Clement; dan (6). Model sosioedukasional Garder.

Ketiga, rumpun Nativis yang kemunculannya dipelopori oleh teori linguistic generatif transformatif yang dicetuskan oleh Noam Chomsky, antara lain; (1). Model nativis LAD 
(language acquisition device) Noam Chomsky; (2). Model monitor Stephen Krashen; (3). Model konstruksi kreatif Dulay dan Burt; (4). Model strategi Bialystok; (5). Model proses Mc.Laughin; (6). Model variable kompetisi Ellis; dan (7). Model interaksionis Ellis.

Keempat, rumpun Humanistis yang berpangkal pada sosiolinguistik yang secara tidak langsung ditopang oleh psikologi humanistiknya Maslow, antara lain; (1). Model komunikasi Hymes; (2). Model akulturasi Scumman; (3). Model akomodasi Giles; dan (4). Model wacana Hatch.

Namun, ke 24 model pemerolehan bahasa tersebut diatas tidak akan dideskripsikan secara detil dalam tulisan singkat ini. Pembahasan secara rinci hanya pada Model Pengondisian Operan Skinner dari rumpun Behavioris, Model Nativis LAD Noam Chomsky dan Model Monitor Stephen D. Krashen yang keduanya ini termasuk dalam rumpun Nativis. Ketiga model dari dua rumpun ini dipilih karena ia dikembangkan oleh psikolog sekaligus linguis, yang dianggap sebagai rumpun yang paling shahih dalam mendeskripsikan teori pemerolehan bahasa dibandingkan dengan 2 rumpun yang lain, yang dikembangkan oleh psikolog yang tidak memiliki latar belakang teori linguistic yang jelas6o.

\section{B. Teori Pemerolehan Bahasa Kedua (Second Language Acquisition Theory)}

1. Model Pengondisian Operan

Model pengondisian operan adalah teori pemerolehan bahasa dari rumpun behavioris yang dikembangkan oleh hlm. 139 .

60Henry Guntur Tarigan, Psikolinguistik, (Bandung : Angkasa, 1985), 
B.F Skinner dalam bukunya yang terkenal tahun 1957 "Verbal Behavior". Model ini merupakan pengembangan lebih lanjut dari teori belajar pengondisian operan dalam psikologi behavioris yang dilandasi oleh filsafat empiris dan linguistic structural Amerika yang beranggapan bahwa bahasa merupakan hasil stimulus - respon antara pembicara dan pendengar, bahasa adalah system bunyi, dan system bunyi ini dianggap sebagai perwujudan bentuk bahasa61.

Dalam pandangan psikologi behavioris perilaku nyata adalah yang dapat diindra, dapat diukur dan dapat dilukiskan secara pasti serta dapat diramalkan. Perilaku nyata ini diperlakukan sebagai hasil belajar. Skinner menyebut perilaku nyata itu salah satunya adalah perilaku verbal. Menurut psikologi behavioris perilaku manusia sepenuhnya dipengaruhi oleh faktor eksternal, terutama faktor lingkungan yang berperan penting dalam mengendalikan perilaku manusia, dan bukan faktor dari dalam diri manusia (faktor internal) terutama faktor kejiwaannya. Senada dengan psikologi behavioris, filsafat empirisme sangat menekankan pengalaman inderawi, sedangkan pengalaman non inderawi tidak menjadi perhatian. Dalam pandangan ini manusia adalah bagian dari alam kebendaan, kertas putih bersih dan licin atau tabula rasa, sehingga manusia dianggap sebagai mahluk yang dapat dibentuk sedemikian rupa sesuai dengan kepentingan dan kebutuhan. Bahkan tipologi dan karakter

61Ibid, dan Djoko Saryono, Pemerolehan.........., hlm. 16 
manusia pun dapat dibentuk dan diwujudkan dalam diri manusia62.

Model pengondisian operan berpandangan bahwa manusia sebagai pembelajar bersifat pasif dan reaktif, karenanya ia terikat pada stimulus dan peneguhan dari luar untuk dapat berperilaku. Dalam hal ini stimulus dan peneguhan selalu datang dari orang lain. Demikian pula perilaku verbal manusia diteguhkan (reinforced) melalui perantaraan orang lain63. Faktor-faktor seperti kreatifitas, inovasi, motivasi, inisiatif dan faktor kejiwaan lainnya bukanlah faktor pendorong utama dalam pemerolehan bahasa.

Menurut pandangan model ini, karena pemerolehan bahasa bergantung sepenuhnya pada faktor lingkungan dan bukan kejiwaan, maka proses pemerolehan bahasa hanya dapat berlangsung melalui pembentukan perilaku atau pembentukan kebiasaan berbahasa64. Pembentukan kebiasaan ini dilakukan dengan jalan memberikan pengondisian operan kepada pembelajar. Menurut Skinner, yang dimaksud dengan pengondisian operan adalah peneguhan atau penguatan respon operan dengan jalan memberikan stimulus peneguh jika dan hanya jika respon terjadi. Perilaku respon operan ini oleh Skinner disebut sebagai variabel terkontrol atau variabel terikat65. Yang dimaksud dengan perilaku respon operan adalah responrespon yang dikeluarkan bagi stimulus-stimulus yang

62Jos D. Parera, Pengantar Linguistik Umum, (Ende Flores : Nusa Indah, 1983), hlm. 99

63B.F. Skinner, Verbal Behavior, (New York : Appleton Century Crofts Inc, 1957), hlm. 13

64 Ibid.

65Ibid, hlm. 14

64 Jurnal Komunikasi dan Pendidikan Islam, Volume 6, Nomor 2, Desember 2017 
tersembunyi, yang terjadi hanya karena perilaku yang telah dikerjakan sebelumnya oleh pembelajar. Jadi, terjadinya perilaku respon operan dikendalikan oleh akibat perilaku sebelumnya66. Dalam pemerolehan bahasa, Skinner membagi perilaku respon operan menjadi 6 macam yaitu yang ia sebut dengan mand, achoic, textual, intraverbal, tact dan autolitic67.

Pertama, Mand yaitu respon operan verbal yang diteguhkan atau dikuatkan oleh karakteristik konsekuensi tertentu dan berada dibawah control fungsional kondisi kondisi yang relevan dengan stimulus. Mand ini dicirikan oleh tautan-tautan unik antara bentuk respon dan peneguhan yang karakteristiknya lebih dapat diterima dalam komunitas verbal yang sudah pasti68. Mand digolongkan ke dalam tipe operan verbal yang dikeluarkan secara tersendiri oleh variabel-variabel yang mengontrolnya69.

Mand bermula pada waktu anak-anak mengeluarkan bunyi secara sembarangan, dan sebagian bunyi itu menyebabkan munculnya peneguhan. Namun demikian menurut Skinner, mand bisa juga berlaku pada remaja dan orang-orang dewasa70. Menurut Skinner wujud mand sendiri bisa bermacam-macam antara lain; (a). permintaan (request); (b). perintah (command); (c). doa atau permohonan (praying or entrety); (d). pertanyaan (question); (e). saran (advice); (f). peringatan (warning); (g). persilaan

66Ibid

67 Ibid, hlm. 33

68Ibid, hlm. $35-36$

69 Ibid, hlm. 56

7olbid, hlm. 39 
(permission); (h). penawaran (offer); (i). panggilan (call); dalam semua wujud mand ini tidak diawali oleh stimulus terdahulu yang menentukan bentuk khusus responnya71.

Kedua, echoic yaitu respon operan berupa pola bunyi yang setara atau mirip dengan stimulusnya. Stimulus verbal akan mendorong munculnya respon yang sama dengan stimulus verbal tersebut72. Dengan kata lain, pembelajar selaku responden menirukan ucapan-ucapan pemberi stimulus. Misal seorang anak menirukan ucapan orangtuanya hubungannya dengan stimulus kata minum. Setiap kali ibunya memberikan air dengan mengucapkan kata minum, si anak akan menirukan ucapan si ibu dengan mengucapkan kata minum, demikian seterusnya. Jadi Echoic merupakan usaha-usaha pembelajar melakukan imitasi atau tiruan terhadap stimulus lisan yang mengarah kepadanya. Pembelajar mencoba melakukan respon imitative dengan jalan mereproduksi bentuk stimulus terdahulu yang auditoris. Dengan demikian, echoic ditentukan oleh stimulus verbal terdahulu yang auditoris73.

Berbeda dengan echoic, respon operan ketiga, textual, ditentukan oleh stimulus terdahulu berupa tulisan atau cetakan74. Menurut Skinner, stimulus ortografis mengontrol operan verbal yang dikerjakan oleh pembelajar. Jadi, textualdapat dikatakan sebagai operan verbal terhadap stimulus ortografis. Sebagai contoh seseorang belajar membaca, kemudian dia mencoba mengingat-ingat dan mereproduksi bacaan yang dibacanya. Proses

71 Ibid, hlm. 185

72I Ibid, hlm. 55

73Ibid, hlm. 185

74lbid, hlm. 186

66 Jurnal Komunikasi dan Pendidikan Islam, Volume 6, Nomor 2, Desember 2017 
mengingat dan mereproduksi ini merupakan respon operan textual si pembelajar, sementara bacaan adalah stimulus ortografis terdahulunya.

Keempat, respon operan intraverbal. Dalam perilaku operan intraverbal vokalisasi anteseden (yang mendahului) mengontrol kondisi-kondisi vokalisasi yang berikutnya. Respon operannya dikontrol dan ditentukan oleh stimulusnya sendiri75. Dalam operan intraverbal, resitasi atau penghafalan menjadi cirri utamanya, bahkan dapat dikatakan bahwa intraverbal ialah respon yang resitatif atau bersifat penghafalan. Skinner memberi contoh sebagai berikut : respon four untuk stimulus two plus two; respon Paris untuk stimulus capital of france; respon how are you? Untuk stimulus fine, thank you yang merupakan respon intraverbal murni; why? Lazimnya merupakan stimulus bagi respon yang dimulai dengan because.........76dan seterusnya.

Echoic, textual dan intraverbal yang sudah dijelaskan diatas stimulus terdahulunya adalah stimulus verbal. Selain stimulus verbal terdapat juga stimulus non verbal yang dirinci oleh Skinner menjadi 2 macam, yaitu audians atau dunia pikiran, dan peristiwa yang digunakan untuk "berbicara tentang". Stimulus yang demikian disebut tact oleh Skinner. Jadi, respon operan kelima, tact, merupakan operan verbal yang responnya ditimbulkan oleh stimulus non verbal. Skinner memberi contoh misalnya, terdapat stimulus warna merah, kemudian pembelajar memahami bahwa objek itu ber-warna merah dan pembicaraan 
memberikan respon dengan ucapan merah!. Selanjutnya pendengar mengucapkan Benar!, yang pada tindak tutur berikutnya peneguhan ini menjadi stimulus peneguhan 77 .

Keenam, operan verbal autoclitic. Operan ini ditautkan dengan tata bahasa dan sintaksis. Menurut Skinner, tata bahasa dan sintaksis merupakan proses autoclitic78. Sejalan dengan itu, autoclitic bersangkutan dengan pemerian negasi, kualifikasi, kuantifikasi, dan yang paling penting adalah konstruksi kalimat. Autoclitic juga bersangkutan dengan pemerian keadaan atau kekuatan respon, misalnya; I guess, I believe, I surmise; bersangkutan dengan pemerian corak atau sikap respon, misalnya; I recall, I demand, I hesitate to say; bersangkutan pula dengan apa yang diharapkan perasaan pembicara yang terungkapkan dengan berbagai cara, misalnya; you might say, I hope you won't think. Jadi autoclitic dicirikan oleh adanya mutu respon, pengekspresian relasi, dan pemberian grammatical framework (kerangka tata bahasa) 79 .

Penjelasan diatas menunjukkan bahwa teori pemerolehan bahasa model pengondisian operan menekankan pada stimulus, respond dan peneguhan. Menurut teori model ini, bahwa proses pemerolehan bahasa mengikuti dan bergantung pada proses bekerjanya stimulus - respon - peneguhan. Hasil pemerolehan bahasa juga bergantung pada bagaimana bekerjanya jaringan stimulus - respon - peneguhan tersebut.

77Ibid, hlm. 84

78Ibid, hlm. 331

79 Ibid

68 Jurnal Komunikasi dan Pendidikan Islam, Volume 6, Nomor 2, Desember 2017 
Dailatus Syamsiyah : Analisis Deskriptif Teori Pemerolehan Bahasa Kedua

\section{Model Nativis LAD (Language Acquisition Device)}

Teori pemerolehan bahasa model Nativis LAD ini dicetuskan oleh Noam Chomsky yang berawal dari kritikankritikannya pada model pengondisian operan Skinner dalam artikelnya yang berjudul A Review of B.F. Skinner's Verbal Behavior (1959). Model ini terformulasikan secara jelas dan utuh konstruknya dalam buku Chomsky yang terbit tahun 1965, Aspect of The Theory of Syntax. Menurut Djoko Saryono model ini dilandasi oleh linguistic generatif transformasi Chomsky dan filsafat rasionalisme Descartes80. Linguistic generatif meyakini bahwa bahasa merupakan cermin pikir manusia dan hasil kecerdasan setiap individu manusia yang selalu baru. Bahasa menurut Chomsky adalah sesuatu yang diciptakan oleh kedinamisan dan kemampuan organisme manusia yang menitikberatkan pada kemampuan kreatifnya81. Sedang filsafat rasionalisme Descartes menekankan pada rasio atau akal budi manusia. Filsafat Descartes memandang manusia sebagai mahluk dualitis, yaitu terdiri dari dua substansi; jiwa dan tubuh. Jiwa adalah pikiran, sedang tubuh adalah keluasan. Dengan demikian tubuh sekedar mesin yang dijalankan oleh jiwa. Karena itu jiwa atau pikiran merupakan komponen paling utama dan penting dalam diri manusia82. Dengan demikian, teori pemerolehan bahasa model Nativis LAD ini dilandasi oleh pandangan konseptual yang

80Djoko Saryono, Pemerolehan..............., hlm. 32

${ }_{81 N o a m}$ Chomsky, Aspect of The Theory of Syntax, (Cambridge, Massachusett : MIT Press, 1965), hlm. 48

${ }_{82}$ Slogan terkenal Descartes "cogito ergo sum" (aku berfikir maka aku ada) adalah rumusan utama filsafat Descartes tentang jiwa atau pikiran. Lihat Juhaya S. Pardja, Aliran-aliran Filsafat dari Rasionalisme Hingga Sekularisme, (Bandung : Alva Gracia, 1987), hlm. 10 
menyangkut diri manusia sebagai pembelajar dan didalam prosesnya memeroleh bahasa.

Manusia -yang terdiri dari tubuh dan jiwa- selalu aktif dan kreatif mengolah masukan-masukan bahasa yang diterimanya, dan tidak bergantung pada adanya stimulus atau peneguhan yang berasal dari faktor eksternal lingkungan terutama orangtua (sebagaimana teori Skinner). Keaktifan dan kreatifitas ini terjadi karena struktur kejiwaan manusia memang bersubstansi demikian. Didalam struktur kejiwaan manusia terdapat piranti yang mengurusi pemerolehan bahasa, yang disebut dengan Language Acquisition Device (LAD) atau Language Acquisition System (LAS) yang menurut Chomsky piranti ini mampu memproses data linguistic yang diterimanya dengan jalan internalisasi. Dengan kata lain, LAD memiliki kemampuan menginternalisasikan masukan data linguistic dan membuat kaidah-kaidah tata bahasa83. Dengan LAD manusia dapat menguasai bahasa dalam waktu relative singkat dengan system yang demikian kompleks dan keberadaannya yang abstrak84. Pandangan ini didukung oleh teori Neurolinguistik yang menyatakan bahwa dalam struktur anatomis manusia terdapat bagian-bagian otak dan saraf tertentu yang mengurusi bahasa. Berdasarkan kajian neurobiologis ditemukan bahwa hemisfer serebral kiri otak manusia bertugas mengurusi bahasas5.

83Noam Chomsky, Aspect of ................, hlm. 55

84Douglas Brown, Prinsip Pembelajaran dan Pengajaran Bahasa, Nurcholis dkk (pent.), (Pearson Education Inc, 2007) hak cipta edisi bahasa Indonesia (2008) oleh Kedutaan Amerika Serikat di Jakarta. Hlm. 20 85Arifuddin, Neuropsikolinguistik, (Jakarta, Rajawali Press, 2010), hlm. 22

70 Jurnal Komunikasi dan Pendidikan Islam, Volume 6, Nomor 2, Desember 2017 
Menurut Mc Neil dalam Douglas Brown, LAD memiliki kemampuan untuk86 ;

a. Memilah-milahkan antara suara manusia dengan suara yang lain

b. Mengorganisasikan kejadian-kejadian linguistic menjadi kelas-kelas

c. tertentu yang secara "sambil jalan" klasifikasi ini disempurnakan

d. Mengatur data linguistic yang sudah diklasifikasikan pada butir

e. Mengadakan penilaian terus menerus dalam rangka membuat system bahasa yang paling sederhana.

Jadi, Language Acquisition Device (LAD) memiliki kemampuan mengolah masukan data linguistic yang diterimanya menjadi kompetensi gramatikal87.

Menurut pemaparan Djoko Saryono, di dalam benak manusia yang sedang belajar bahasa, LAD belajar mengolah masukan-masukan data linguistic dengan jalan membentuk hipotesis-hipotesis tentang system bahasa dan kaidah-kaidah bahasa yang dipelajari. Pembelajar berupaya mengoperasikan LAD nya untuk membentuk hipotesis tentang kaidah bahasa yang dipelajari dan memperbaikinya. Hal ini dikerjakan secara bawah sadar. Hipotesis yang telah ditetapkan secara bawah sadar kemudian diuji dalam pemakaian bahasa sehari-hari oleh pembelajar. Hal ini mengakibatkan berubahnya hipotesis pembelajar tentang kaidah bahasa yang dipelajarinya dan disesuaikannya hipotesis itu secara teratur. Hipotesis yang hlm. 80

87Noam Chomsky, Aspect of hlm. 56 
salah atau keliru diperbaiki sampai sempurna dan hipotesis yang benar menjadi pengetahuan tentang kaidah system bahasa yang dipelajari. Dengan jalan demikianlah pembelajar mengembangkan system bahasanya menuju system kaidah yang sempurna seperti yang dituturkan oleh orang dewasa. Pembelajar mengembangkan system kaidah bahasanya secara teratur dan sistematis 88 .

Berkaitan dengan hipotesis tersebut, perlu diketahui bahwa; pertama, LAD tidak berisi bahasa tertentu, karena LAD tidak berhubungan langsung dengan bahasa tertentu. Oleh sebab itu, bahasa yang dihipotesiskan oleh pembelajar bergantung pada bahasa yang menjadi masukannya. Kedua, LAD pada dasarnya adalah "mesin" pengolahan bahasa yang terdapat dalam struktur kejiwaan manusia, sehingga selalu siap menerima masukan data linguistic apapun tanpa pemilihan terlebih dulu. Bahasa apapun akan dapat diolahnya. Tidak ada bahasa tertentu yang diistimewakan oleh LAD untuk dihipotesiskan. Bahasa apapun yang menjadi masukannya, pasti dihipotesiskan89.

Mekanisme kerja LAD dalam pemerolehan bahasa menurut Chomsky melalui tiga komponen yaitu :masukan, pengolah, dan keluarango. Masukan berisi data linguistic primer yang merupakan ujaran orang dewasa dengan bahasa tertentu. Pengolah berisi LAD dengan prinsipprinsip kerja sebagaimana dikemukakan diatas. Keluaran berisi kompetensi gramatikal bahasa yang dipelajari pembelajar berupa tata bahasa yang pada akhirnya

88Djoko Saryono, Pemerolehan hlm. 37

89Ibid, hlm. 38

90Noam Chomsky, Reflection on Language, (New York : Pantheon Books, 1975), hlm. 118 
terwujud dalam ujaran pembelajar. Dalam mekanisme ini, LAD adalah komponen utama dalam proses pemerolehan bahasa. Tidak ada komponen lain, baik komponen kognitif maupun komponen afektif, selain LAD yang beroperasi sewaktu proses pemerolehan bahasa berlangsung. Menurut Chomsky proses pemerolehan bahasa mengikuti strategi umum tanpa dipengaruhi faktor-faktor lain. Melalui inilah Chomsky mencetuskan gagasannya tentang tata bahasa universal (universal grammar), yang meyakini bahwa faktor linguistic lebih menentukan proses pemerolehan bahasa daripada faktor kognitif91. Universal grammar merupakan sifat yang sudah melekat dalam pikiran manusia yang terdiri atas seperangkat prinsip umum yang diterapkan pada semua bahasa, ia bertautan erat dengan LAD92. Dengan demikian, pemerolehan bahasa mengikuti tahapantahapan yang teratur dan sistematis. Seseorang yang belajar bahasa akan memperoleh bahasa yang dipelajarinya secara berangsur-angsur sesuai dengan universal grammar pemerolehan bahasa yang terdapat di dalam LAD.

Meskipun menuai kritik, model pemerolehan bahasa dengan melalui LAD menginspirasi banyak teori pemerolehan bahasa yang meyakini bahwa manusia memiliki piranti khusus yang memproses bahasa. Francescato dalam FJ. Monks menilai LAD tidak bisa diuji secara empiris, ia hanyalah spekulasi rasional-logis yang hanya hidup di dalam pikiran manusia. Paradigma teori Ted K. Bathia And William C. Ritchie, The Handbook of Bilingualism, (California : Blackwell Publishing Ltd, 2006), hlm. 121 ${ }_{92}$ Noam Chomsky, Reflection.................., hlm. 120 
nativis LAD ini tidak memberi penjelasan memadai tentang mekanisme kerja LAD pada anak-anak yang bilingual dan lingkungan diglosia93. Senada dengan pandangan Francescato, beberapa pemikir lain juga menilai proposisi LAD terlalu filosofis dan cenderung fiktif karena tidak ada dalam kenyataan neurobiologis atau fisikal. Beberapa pendukung teori Chomsky memberi argumentasi bahwa meskipun LAD tidak bisa dibuktikan secara empiris, namun keberadaannya secara rasional-logis dapat diterima, sebab tidak mungkin manusia dapat memperoleh bahasa yang sangat kompleks, atau belajar bahasa, tanpa mempunyai alat yang khusus untuk itu94.

3. Model Monitor

Model pemerolehan bahasa "Monitor" dikemukakan oleh Stephen D. Krashen seorang linguis Amerika dalam bukunya Second Language Acquisition and Second Language Learning tahun 1981. Berbeda dengan 2 teori model pemerolehan bahasa yang -sudah disebutkan di atas- mengarahkan pemerolehan bahasa pada anak-anak, model Monitor ini dikhususkan oleh Krashen untuk pembelajar dewasa yang sedang berusaha memperoleh bahasa kedua. Menurut Krashen pemerolehan bahasa pada orang-orang dewasa memiliki cirri khas tersendiri, meskipun terdapat keteraturan universal di dalamnya.

Model monitor ini banyak diilhami oleh pandangan linguistic generatif transformasi Chomsky yang nativis dan filsafat rasionalisme kritis Immanuel Kant. Ajaran Filsafat Kant ialah bahwa pengetahuan dapat dikaji dari akal budi

93FJ. Monks, Psikologi Perkembangan, (Yogyakarta : Gadjah Mada University Press, 1987), hlm. 137 94Djoko Saryono, Pemerolehan. , hlm. 44

74 Jurnal Komunikasi dan Pendidikan Islam, Volume 6, Nomor 2, Desember 2017 
(verstand), rasio (vermunft) dan pengalaman indrawi; Pengetahuan merupakan sintesis unsur apriori dengan unsur aposteriori; dan pengetahuan merupakan hasil "kerja sama" antara unsur pengalaman inderawi dan keaktifan akal budi95. Secara umum pengaruh kedua pandangan tersebut tampak pada konstruksi dan paradigma model monitor yang dicetuskan Krashen menjadi 4 (empat) hipotesis, yaitu hipotesis pemerolehan dan belajar, hipotesis urutan alamiah, hipotesis monitor, dan hipotesis penyaring afektif96.

Pertama, hipotesis pemerolehan dan belajar (acquisition and learning hypothesis). Menurut Krashen orang dewasa memiliki dua system independent untuk menguasai bahasa kedua, yaitu system pemerolehan (acquisition) dan system belajar (learning). Menurut Krashen, pemerolehan (acquisition) adalah proses penguasaan bahasa kedua secara bawah sadar. Formulasi kaidah-kaidah bahasa sasaran dilakukan dan diinternalisasikan secara bawah sadar. Dengan demikian, pemerolehan bahasa berlangsung secara alamiah tanpa kondisi manipulatif97. Hal ini hampir sama dengan proses pemerolehan bahasa pertama oleh anak-anak. Dalam pemerolehan ini yang dipentingkan adalah isi pesan, bukan bentuk linguistiknya atau gramatika wacana. Pembelajar dalam hal ini tidak tanggap terhadap kaidah-kaidah bahasa kedua. Bahkan pembelajar biasanya tidak bisa menjelaskan mengapa ia menggunakan suatu struktur tertentu ketika berbicara dalam suatu kesempatan, dan di 
kesempatan yang lain ia berbicara dengan struktur yang berbeda pula. Hal ini berarti pembelajar lebih tahu berbahasa daripada tahu tentang bahasa yang digunakannya. Jika terjadi koreksi atas suatu kesalahan dalam bertutur, hal itu ia lakukan secara intuitif saja, dan bukan didasari oleh kesadaran rasional. Proses ini menurut Krashen dikendalikan oleh suatu strategi pemerolehan bahasa yang universal yang terdapat pada setiap pembelajar. Masukan data primer linguistic yang didengar oleh pembelajar hanyalah berfungsi untuk mengaktifkan strategi universal tersebut. Suatu pandangan yang paralel dengan teori nativis LAD Chomsky.

Di sisi lain system belajar (learning) dimaknai sebagai suatu proses pemilihan kaidah-kaidah bahasa kedua secara sadar-rasional-kognitif dan berlangsung di lingkungan artificial yang formal manipulatif9s. Dalam proses ini terjadi asimilasi dan rasionalisasi terhadap kaidah-kaidah bahasa kedua sebagai hasil dari pengajaran formal tentang tata bahasa. Dalam system belajar, data primer linguistic yang masuk hanya digunakan untuk berlatih oleh pembelajar bahasa kedua, serta untuk menguji secara sadar penguasaannya terhadap kaidah bahasa. Jadi data primer linguistic hanya digunakan untuk mencocokkan kebenaran bentuk linguistic yang digunakan, bukan untuk menyampaikan isi pesan99.

Kedua, hipotesis urutan alamiah. Menurut Krashen hipotesis ini mengacu pada urutan-urutan penguasaan struktur gramatikal yang berlaku universal dan tidak

98Ibid, hlm. 31

99Ibid, hlm. 42

76 Jurnal Komunikasi dan Pendidikan Islam, Volume 6, Nomor 2, Desember 2017 
berkorelasi dengan kesederhanaan bentuk. Urutan pemerolehan unsur-unsur linguistic ini berlangsung secara alami, dan diperoleh oleh setiap pembelajar hampir secara bersamaan. Misalnya struktur awalan "me" dalam bahasa Indonesia akan diperoleh lebih awal oleh pembelajar daripada struktur yang berawalan "ber". Dalam bahasa Inggris, susunan simple present tense akan diperoleh dan dikuasai terlebih dulu oleh pembelajar daripada struktur simple past tense. Demikian pula dalam bahasa Arab, biasanya pembelajar akan menguasai terlebih dulu susunan mubtada' dan khabar, daripada susunan fiil, fail dan maf'ul dan seterusnya.

Ketiga, Hipotesis Monitor. Pada hipotesis pertama diatas telah dijelaskan bahwa pemerolehan dan belajar memiliki ciri khas dan fungsi yang berbeda. Pemerolehan (acquisition) menghasilkan system konstruksi kreatif yang merupakan kompetensi yang diperoleh secara alamiah. Sedangkan belajar (learning) menghasilkan system bahasa untuk monitor yang merupakan kompetensi yang dipelajari dengan pengondisian tertentu. Monitor merupakan proses penyuntingan, perbaikan, dan pengoreksian wacana baik sebelum maupun sesudah wacana itu dituturkan. Menurut Krashen belajar tidak banyak membantu menyunting, memperbaiki dan mengoreksi tata bahasa yang diperoleh melalui pemerolehan, belajar hanya memonitor tata bahasa pertuturan dan bukan menentukan kelancaran dan kemahiran pertuturan 100 .

Keempat, Hipotesis Penyaring Afektif, yaitu bahwa variable afeksi memainkan peranan yang sangat penting

100Stephen D. Krashen, Second Language hlm. 46 
dalam pemerolehan bahasa kedua. Penyaring afeksi akan menjadi longgar jika pembelajar bahasa kedua dalam keadaan tenang, senang, tidak gugup atau takut, dengan demikian informasi yang diperoleh bisa masuk dengan mudah ke dalam otak. Dalam pengajaran bahasa kedua, bila pengajar berhasil menciptakan suasana kelas yang segar dan bebas rasa takut, maka masukan informasi akan terresap lebih dalam karena pembelajar lebih berani mengambil resiko. Sebaliknya jika pembelajar selalu merasa takut, gelisah, lelah, malu dan segan, maka penyaring afektif akan tertutup rapat sehingga masukan yang diterima tidak bisa dicernakan ke dalam otak. Sehingga dapat dikatakan pemerolehan bahasa kedua tidak berhasil dengan baik101.

Dari semua hipotesis yang dikemukakan Krashen ini dapat disimpulkan bahwa penyaring afektif merupakan penghalang bagi masukan-masukan bahasa kedua (B2). Diterima atau tidaknya masukan B2 sangat tergantung pada kondisi penyaring afektif dari pembelajar.

\section{Kesimpulan}

Pemerolehan bahasa kedua senyatanya adalah sebuah hasil dari proses interaktif antara "piranti" khusus yang menangani bahasa dan merupakan potensi bawaan setiap manusia, yang disebut Chomsky sebagai Language Acquisition Device (LAD) atau Language Acquisition System (LAS) atau disebut Krashen sebagai unconscious potency (potensi bawah sadar), dengan proses belajar bahasa yang dilakukan secara

101 Ibid, hlm. 48

78 Jurnal Komunikasi dan Pendidikan Islam, Volume 6, Nomor 2, Desember 2017 
sadar-rasional-kognitif di lingkungan yang alami maupun yang berlangsung di lingkungan artificial yang formal manipulative.

Dalam perspektif neurologi, kegiatan berbahasa berada pada bagian-bagian tertentu otak manusia, yaitu otak kiri mengurusi produksi ujaran dan otak kanan terlibat dalam kegiatan membaca dan relevansi antara gerakan psikomotor dengan memori bahasa. Dengan demikian, cukup fair untuk menyatakan bahwa keberhasilan setiap individu pembelajar bahasa kedua ditentukan oleh kegiatan - kegiatan belajar yang bersifat kognitif (bagian dari kerja otak kiri), sebuah pandangan yang parallel dengan teori Skinner, dan faktor afektif yang ekstroversif (yang merupakan bagian dari potensi otak kanan), parallel dengan pandangan Krashen dan Chomsky diatas. Allahu A'lam 


\section{DAFTAR PUSTAKA}

Arifuddin, Neuropsikolinguistik, (Jakarta, Rajawali Press, 2010)

Bathia, Ted K., William C. Ritchie, The Handbook of Bilingualism, (California : Blackwell Publishing Ltd, 2006)

Brown, Douglas, Prinsip Pembelajaran dan Pengajaran Bahasa, Nurcholis dkk (pent.), (Pearson Education Inc, 2007) hak cipta edisi bahasa Indonesia (2008) oleh Kedutaan Amerika Serikat di Jakarta.

Chomsky, Noam, Aspect of The Theory of Syntax, (Cambridge, Massachusett : MIT Press, 1965)

Chomsky, Noam, Reflection on Language, (New York : Pantheon Books, 1975)

Djoko Saryono, Pemerolehan Bahasa : Teori dan Serpih Kajian,

(Malang : Nasa Media, 2010)

Henry Guntur Tarigan, Psikolinguistik, (Bandung : Angkasa, 1985).

Jos D. Parera, Pengantar Linguistik Umum, (Ende Flores : Nusa Indah, 1983)

Juhaya S. Pardja, Aliran-aliran Filsafat dari Rasionalisme Hingga Sekularisme, (Bandung : Alva Gracia, 1987)

Krashen, Stephen D., Second Acquisition And Second Language Learning, (Pergamon Press Inc, University of Southern California : 1981)

Monks, FJ, Psikologi Perkembangan, (Yogyakarta : Gadjah Mada University Press, 1987)

Skinner, B.F., Verbal Behavior, (New York : Appleton Century Crofts Inc, 1957) 